Proceedings of the 2010 Winter Simulation Conference

B. Johansson, S. Jain, J. Montoya-Torres, J. Hugan, and E. Yücesan, eds.

\title{
A SIMULATION STUDY TO INCREASE THROUGHPUT IN AN ENDOSCOPY CENTER
}

\author{
Martha A. Centeno \\ Florida International University \\ Industrial and Systems Engineering \\ Miami, FL 33199, USA
}

Helida R. Dodd

Dodd Consulting Group

10223 SW 89 Street

Miami, FL 33176, USA

\author{
Manuel Aranda \\ Yuly Sanchez \\ Florida International University \\ Industrial and Systems Engineering \\ Miami, FL 33199, USA
}

\begin{abstract}
We present a simulation study to increase the throughput at an Endoscopy center. The center has the capacity to process up to 80 patients a day. However, they were only processing about 50 patients/day, on average. We have built a simulation model to better understand the causes of this low throughput and to determine the worthiness of some proposed changes the center's current operational policies. We examined a fraction of a factorial design of seven factors at two or three levels each. Results helped determine that two perceived causes for the formation of bottlenecks actually did not have much impact, whereas the policy to assign rooms, which was never suspected, has a lot to do with it. We were also able to understand that a major part of the problem is rooted in customers arriving too early for their procedures. We also have identified new venues for future research.
\end{abstract}

\section{INTRODUCTION}

We present a simulation study conducted at an Endoscopy Center in Miami, Florida. The center has 7 rooms, with a capacity of 14 time slots per room for an estimated 98 patients/day. The Center is part of the largest not-for-profit health care organization in the region, with an outstanding reputation for medical and service excellence. Accredited by AAAHC (Accreditation Association for Ambulatory Health Care), the purpose of the Endoscopy Center is to provide the community with a technologically advanced, stateof-the-art facility that offers efficient, cost-effective care. The Center performs over 14,000 procedures per year, including Colonoscopy, Flexible Sigmoidoscopy, and Upper Endoscopy.

When we began the study, the center was processing about 50 patients/day only. There were several theories for both the causes of the low throughput, and for actions that could be taken to increase it. Simulation modeling has been rapidly gaining acceptance among healthcare managers because it is an excellent tool to play a series of what-if scenarios to better understand the causes as well as to see beforehand the impact of some of the proposed solutions to increase throughput (Garcia et al. 1995; Alvarez and Centeno 2000; Centeno et al. 2000; Centeno et al. 2001). We set up a target throughput of 80 patients/day. 
This paper is organized as follows: Section two provides a description of the Endoscopy system. Section three discusses some interesting findings that came to light when we conducted the analysis of historic records to establish input for the simulation model. Section four describes the design of the model, which was written in ARENA (Kelton and Sadowski 2004), and the experimental conditions. Section 5 gives a discussion of the results. Lastly, section six summarizes the conclusion of this effort, and some potential extensions.

\section{THE ENDOSCOPY SYSTEM}

The system under study has seven rooms, where seven single or combined procedures are performed (Table 1). The working schedule allows for 98 times slots among all 7 rooms; each time slot is 30 minutes. The facility operates as $100 \%$ appointment facility, in other words, no walk-ins are allowed. The scheduling policies do allow for changes up to the previous day of the procedure; however, the procedures should preferably be scheduled at least 3 days in advance. Time slot availability for actual procedures is based on a block schedule for the 22 doctors that the Center works with. Historical records were used to determine the duration of each procedure type. Similarly, the number of registered nurses (RNs) and registrations clerks also vary throughout the day according to a schedule (Table 2).

Table 1: Procedures Percentage and Duration

\begin{tabular}{|l|l|l|l|}
\hline Procedures & Description & $\%$ & Procedure Time \\
\hline COL & Colonoscopy & $56.3 \%$ & Erlang $(3.35,5)$ \\
\hline GST & Gastroscopy & $18.4 \%$ & $0.5+$ Lognormal $(6.44,4.69)$ \\
\hline C/G & Colon/Gastro & $23.2 \%$ & $7.5+$ Weibull $(16.3,1.65)$ \\
\hline G/E & Gastro/Ent & $0.7 \%$ & Uniform $(9,12)$ \\
\hline G/F & Gastro/Flex Sig & $1.0 \%$ & Triangular $(4,5,16)$ \\
\hline CGE & Col/Gastro/Ent & $0.3 \%$ & Uniform $(14,26)$ \\
\hline ENT & Enteroscopy & $0.1 \%$ & Uniform $(9,12)$ \\
\hline
\end{tabular}

Table 2: Resources Data

\begin{tabular}{|l|c|c|c|c|c|}
\hline Resource & Pre/post Op Beds & $\begin{array}{c}\text { Director } \\
\text { 1st. Impressions }\end{array}$ & Doctors & $\begin{array}{c}\text { Alternate Recovery } \\
\text { Chairs }\end{array}$ & Registrars \\
\hline Available & 20 & 1 & 2 to 7 & 4 & 1 to 4 \\
\hline Resource & $\mathrm{RN}$ & Rooms & Scheduler & Anesthesiologists & \\
\hline Available & 1 to 12 & 7 & 1 & 2 & \\
\hline
\end{tabular}

Once a patient is referred by a physician, a schedule time and date is set by the scheduler. The patient then goes through a pre-assessment activity to capture personal information. Some of the patients also undergo a pre-registration activity to capture all medical and insurance information. On the day of the surgery, the patient is expected to arrive to the facility 1 hour prior to the actual procedure so that he/she can go through registration and pre-op activities in a timely fashion. Patients are also expected to arrive with a companion, or to have made arrangements to have someone pick them up after the procedure has been completed, as they are not yet in a condition to drive. When they arrive, the patient is greeted by the Director of First Impressions. This individual is in charge of three things: 1) checking that indeed the patient has arrived on the correct day, 2) routing the patient to the next step, and 3) ensuring that the work load in the registration area is relatively balanced (cyclical assignment of patient to registrar). Once a patient has been properly registered, an RN will come for the patient as soon as a Pre/Post Op Bed is available. Once at the bed, the RN completes the pre-op activities and notifies anesthesiologist and doctor that the patient is ready for the procedure. The duration of the procedure depends on the nature of the procedure itself as shown in Table 1. Upon completion of the procedure, the anesthesiologist returns the patient to the Pre/Post Op bed area, where the RN is in charge of the patient until the patient recovers from 
the anesthesia. At that moment, the patient will be discharged if the relative of the patient is on-site, or the patient will be transferred to one of the alternate recovery chairs to wait for the relative.

\section{ESTABLISHING INPUTS FOR THE SIMULATION MODEL}

To establish inputs similar to those shown in Table 1, we examined historical records as well as observed the system for several weeks. Data sets collected were analyzed in regards to 1) patient arrival times, 2) registration times, 3) frequency of each procedure, 4) duration of the procedures, 5) cancellations and no shows, 6) duration of pre-op and post op activities, 7) room turnaround times, and 8) schedules of the various registrars, nurses, and doctors. We have summarized the results of these analysis in Tables 3 and 4. We present some findings that we considered were interesting; however, the schedules of the various resources are not shown as we are not in liberty to disclose them.

Table 3: Summary of Input Analysis

\begin{tabular}{|c|c|c|}
\hline Activity & Distribution & $\%$ \\
\hline Pre-Registered & Erlang $(2.02,3)$ & $32 \%$ \\
\hline Non-Registered & $\operatorname{Gamma}(2.48,3.25)$ & $68 \%$ \\
\hline Pre-Op Admission & Triangular $(16.5,17.6,56.5)$ & \\
\hline Discharge & $\operatorname{Normal}(35.3,14.2)$ & \\
\hline Receive - Post Op & Uniform $(0.5,3.5)$ & \\
\hline Room Turn Around & $9.5+\operatorname{Lognormal}(13.8,15)$ & \\
\hline \multicolumn{3}{|c|}{ Appointment } \\
\hline Kept & Cancellations & No Shows \\
\hline $95.60 \%$ & $3.10 \%$ & $1.30 \%$ \\
\hline
\end{tabular}

Table 4: Arrivals Summary

\begin{tabular}{|c|c|c|c|c|c|}
\hline & $\%>90 \mathrm{Min}$ & $\%>60 \mathrm{Min}$ & $\%>30 \mathrm{Min}$ & $\%$ & Lag Time Distribution \\
\hline Early $=$ & $5.07 \%$ & $8.73 \%$ & $38.03 \%$ & $67.36 \%$ & User defined \\
\hline On Time $=$ & & & & $21.25 \%$ & \\
\hline Late $=$ & $0.00 \%$ & $3.33 \%$ & $16.67 \%$ & $11.39 \%$ & Exponential( 13.1) \\
\hline $\begin{array}{l}\text { Differeno } \\
\text { Estimate } \\
\text { T-Test of }\end{array}$ & $\begin{array}{l}=\text { mu (Only } \\
\text { c difference } \\
\text { ifference }=\end{array}$ & $\begin{array}{c}r(y)-\text { mu } \\
15.50 \\
\text { (vs not }\end{array}$ & $\begin{array}{l}\text { Ily Abs La } \\
95 \% \text { CI } \\
\text { T-Value }\end{array}$ & $\begin{array}{l}\text { diff } \\
10\end{array}$ & $\begin{array}{cll} & (11.21, & 19.80) \\
= & 0.000 & D F=312\end{array}$ \\
\hline
\end{tabular}

\subsection{Analysis of Arrivals Lag Time}

When we began the study, there was a perception that the low throughput was due, in part, to patients arriving late. We defined being late (or early) as arriving 5 or more minutes after (or before) the scheduled arrival time (which is $1 \mathrm{hr}$ before the procedure start time). As we looked at the historic records, we realized that late arrivals occur only $11.39 \%$ of the time (Table 4), and furthermore the length of the lateness (lag time) is mostly under 30 minutes ( $80 \%$ of the time). On the other hand, early arrivals occur $67.36 \%$ of the time, and about $52 \%$ of the time, the length of the lag time is over 30 minutes. So the problem are not the late arrivals, rather the early arrivals. We also noticed that the behavior of lag time was different for late and early arrivals (Table 4 and Figures 1 and 2). These results were a bit of a surprise, but further study confirmed that indeed when a patient is early, there is a high chance the patient may be taken into the Pre-op area out of order (ahead of its schedule), causing doctors to be idle because their on- time patient cannot be "Pre-Oped." 


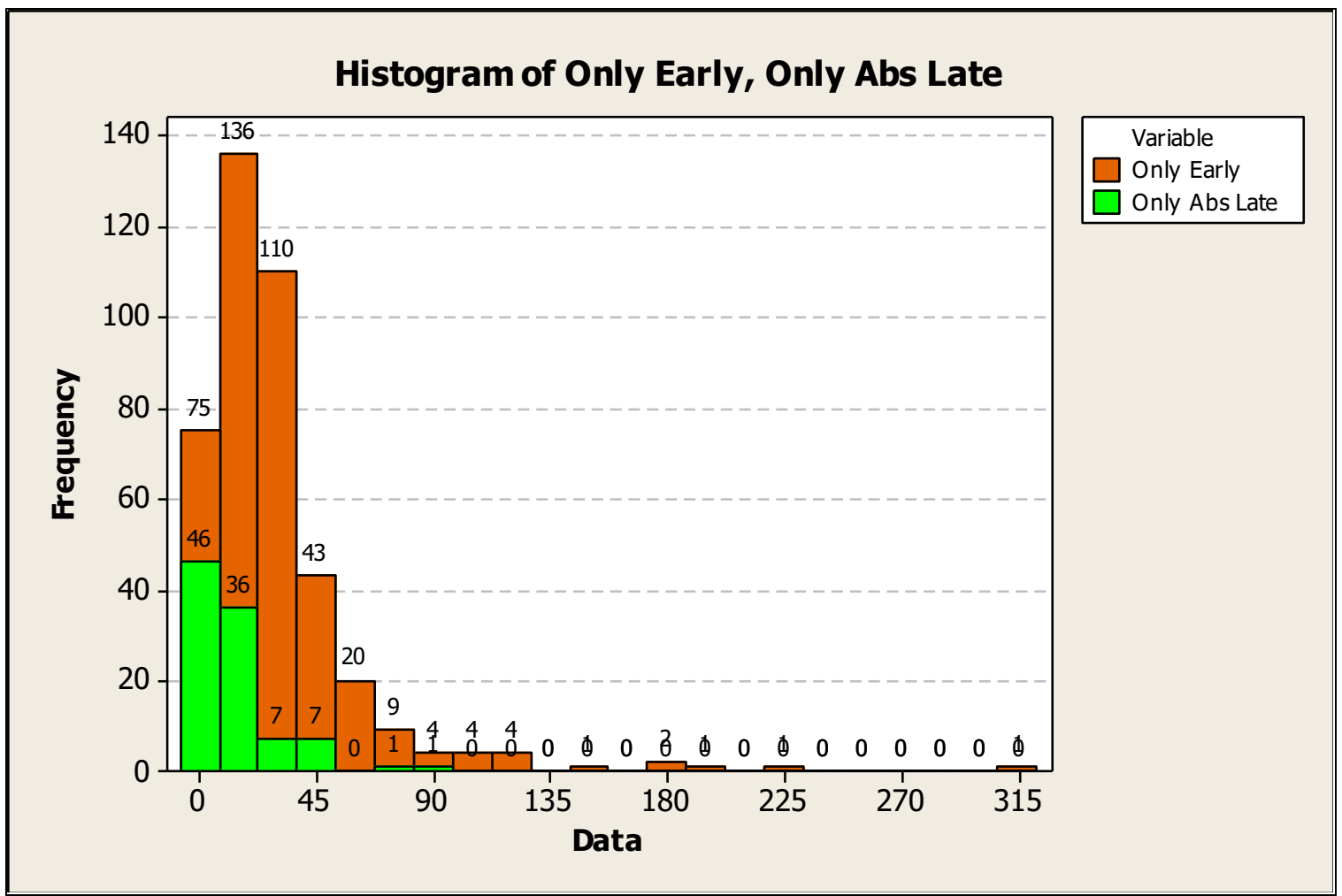

Figure 1: Histogram of Lag Time for Late and Early Arrivals



Figure 2: Box Plot of Lag Time for Late and Early Arrivals 


\subsection{Analysis of Registration Times}

Another perceived cause for the low throughput was the registration time. It was believed that registration was taking too long, either because the registrars were slow, or because they did not have enough registrars, which was causing patients to wait to be registered for an unacceptable long time.

Once the appointment date and time have been selected, patients may be contacted by one of the registrars to collect insurance and medical information. However, this contact with the patient is dependent on the time availability of the registrars. Thus, on the day of the procedure, the patient may or may not be pre-registered. As suspected, there is indeed a difference on the time spent at the registration depending on whether or not the patient has been pre-registered (Table 5 and Figure 3). However, this statistical analysis is not enough to determine the impact of the longer time for non-registered patients in the total flow time. This piece of the puzzle was answered by the simulation results. As shown in Figure 4, the contribution of the wait time for the registrar to the total wait time a patient experiences is no more than $5 \%$ under various alternatives of the system. Clearly, the registration activity is not holding back the patients; in other words, it is not the bottleneck.

Table 5: Registration Times Summary

\begin{tabular}{|c|c|c|}
\hline Registration Status & $\%$ & Registration Time \\
\hline Pre-Registered & $32 \%$ & Erlang(2.02, 3) \\
\hline Non-Registered & $68 \%$ & Gamma(2.48, 3.25) \\
\hline Difference $=$ mu (Times No Pre Reg) & - mu (Times Pre Reg) \\
Estimate for difference: 2.410 & 95\% CI for difference: $\quad(1.623,3.197)$ \\
T-Test of difference $=0$ (vs not $=$ ) : T-Value $=6.01 \quad$ P-Value $=0.000 \quad$ DF $=646$ \\
\hline
\end{tabular}

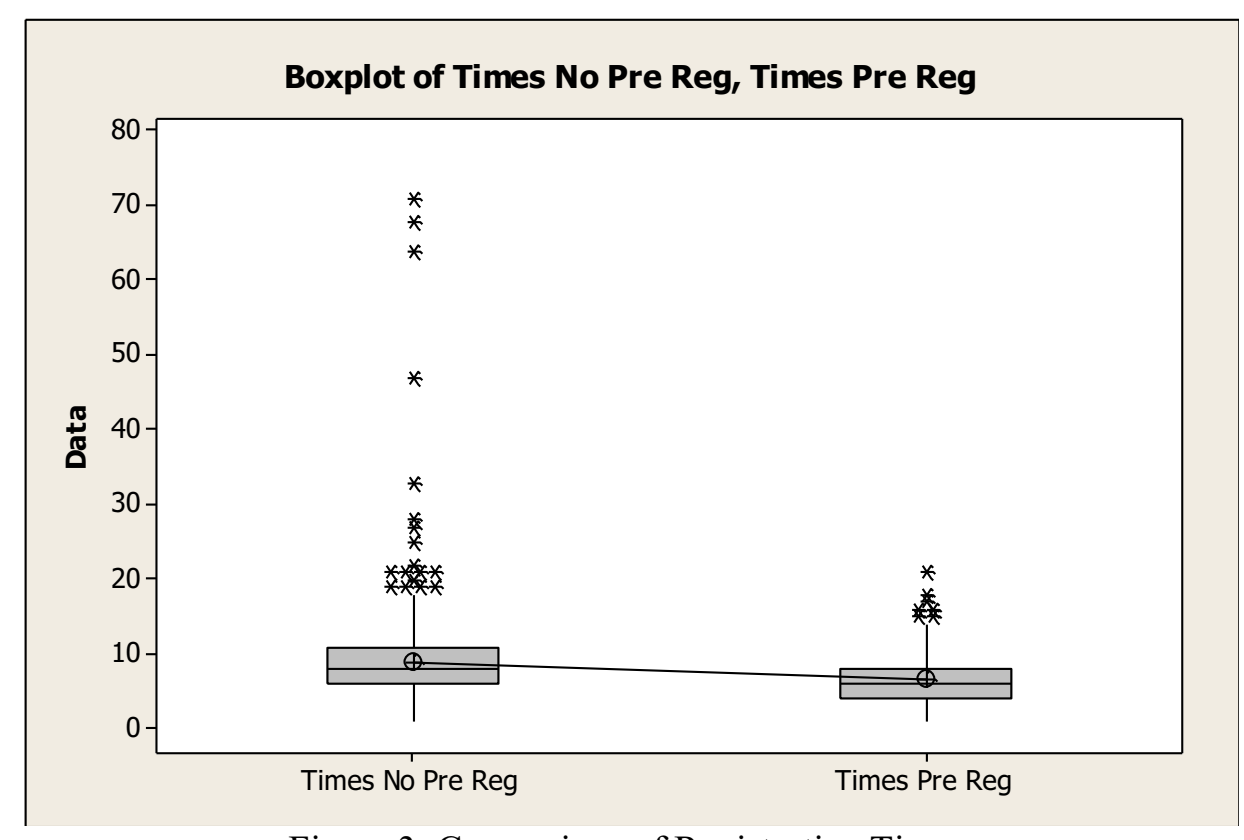

Figure 3: Comparison of Registration Times 


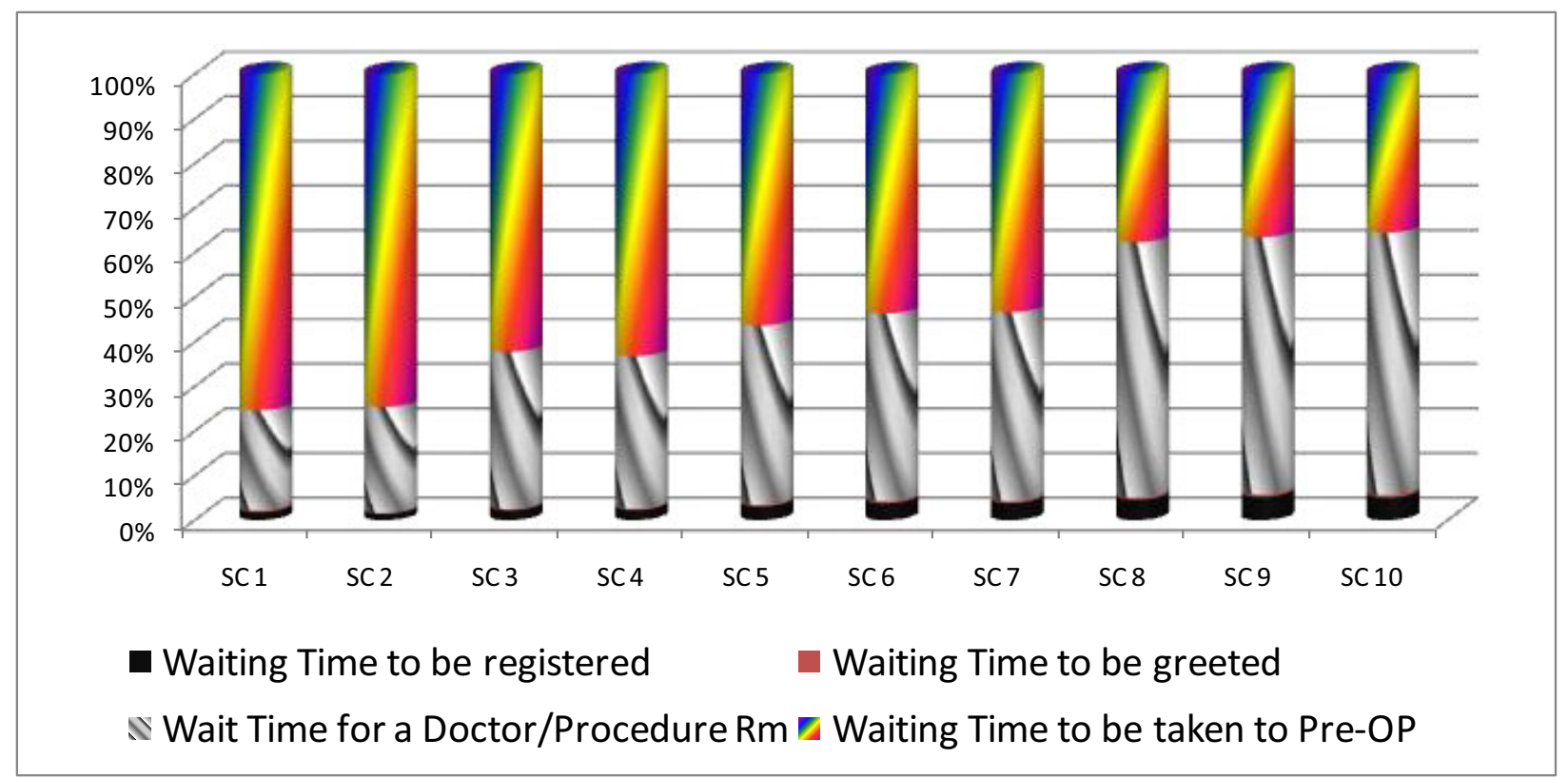

Figure 4: Wait Time Contribution

\section{THE SIMULATION MODEL}

The ARENA model is very straight forward. The schedule of patients is generated at the beginning of each simulated day. The experimentation has been done for a period of 5 days, i.e., a complete working week. Therefore, all schedules for resources span over a week. The model was verified and validated using walkthroughs and comparing the results to a benchmark historical data set.

Once it is time for the simulated patient to show up in the system, it is sent to the parking lot area, where we have collected information in regards to the utilization of the parking spaces. As the patient approaches from the parking lot to the greeter's area, an accompanying entity is produced to represent the relative that will take the patient back home. We have assumed that all relatives wait for the patient. However, some patients are transported by commercial transportation, so there is no one actually waiting for them until the estimated discharge time realizes. There was no data to estimate the percentage of the time that this happens, so we had to leave it out. From this point forward, the simulated patient is routed according to the flow process described previously in Section 2.

\subsection{Assumptions}

We developed the simulation model under the following assumptions. These assumptions were established in consultation with management:

- All patients' companions arrive with the patient and stay in the waiting area until the patient is discharged.

- There is always an anesthesiologists available.

- Doctors could perform back to back procedures if necessary.

- There is a demand of at least 80 procedures per day, but it is not accepted due to bottlenecks.

- RN's schedule may be changed.

- Additional doctors and RNs may be hired.

- If a resource is scheduled to work, it will show up for work. In case this is not the case, a replacement for the resource is assumed to be available. 


\subsection{Experimental Conditions}

We designed a factorial experiment to explore the various ideas recommended by stakeholders. Seven factors were identified, each with a different number of levels as shown in Table 6 .

Table 6: Experimental Factors

\begin{tabular}{|c|c|c|c|c|c|c|}
\hline & \multirow{2}{*}{ Factor } & \multirow{2}{*}{ Levels } & \multicolumn{4}{|c|}{ Levels } \\
\hline & & & $\mathrm{a}$ & $\mathrm{b}$ & $\mathrm{c}$ & $\mathrm{d}$ \\
\hline F1 & Scheduling Rule & 3 & $\begin{array}{l}\text { Probabilistic } \\
\text { (0 to } 7)\end{array}$ & Constant 5/slot & $\begin{array}{c}\text { Constant } \\
1 @ 4,12 @ 6,1 @ 4 \\
\end{array}$ & \\
\hline $\mathrm{F} 2$ & RN Schedule & 3 & As-Is & $\begin{array}{l}\text { shift down } 15 \\
\min \end{array}$ & $\begin{array}{l}\text { shift down } 30 \mathrm{~min} \\
\& \text { add } 0.2 \text { RN FTE }\end{array}$ & $\begin{array}{c}\text { shift down } 30 \\
\text { min \&add } 1.5 \\
\text { RN FTE }\end{array}$ \\
\hline F3 & DR Schedule & 2 & As-Is & $\begin{array}{c}\text { Add 2: 1@7 / } \\
\text { 1@1 } \\
\end{array}$ & & \\
\hline $\mathrm{F} 4$ & Pre-Admit & 3 & No & Yes $(50 \%)$ & Yes $(75 \%)$ & \\
\hline F5 & Beds & 2 & 20 & 24 & & \\
\hline F6 & Room Assignment & 2 & As Is & Random & & \\
\hline F7 & Discharge Time & 2 & As Is & Reduce by $25 \%$ & & \\
\hline
\end{tabular}

1. Scheduling Rule: This factor is used to vary the number of appointments to generate per time slot. Under the system prior to the study, some time slots could be fully filled, whereas others would be empty or only have a couple of patients. An alternative is to have 5 patients scheduled per time slot, uniformly throughout the day. A second alternative is to have the end time slots (start and end) with 4 patients only, whereas the time slots in the middle would have 6 patients each. Under both alternatives, there would be 80 patients processed.

2. RN Schedule: We explored three alternatives to the current schedule. The first one involved shifting down the current schedule by $15 \mathrm{~min}$ to have more RNs at the beginning of the day. The schedule of the doctors starts 1 hour after that of the registrars' and RNs'. The other two are a combination of shifting down the schedule and adding additional RN FTE's.

3. Dr Schedule: One alternative was explored, namely shifting the schedule of some doctors such that there are 2 additional doctors at the beginning of the day. Historic records, observations, and the simulation of the AS-IS system clearly showed that the backlog begins to form around 7 AM in the morning when the Center is not yet working at full speed.

4. Pre Admit: Management has been interested in checking to see if they should pre admit patients or not. By doing this, the pre-op time would be reduced. Management and nurses estimated that the impact could be as low as $50 \%$ and as high as $75 \%$ reduction of the pre-op time.

5. Beds: One alternative that needs to be considered is the conversion of the alternate recovery chairs into permanent pre/post op beds.

6. Room Assignment: Doctors perform the procedures in the room of their preference. However, we wanted to explore if the rooms and doctors' utilization would improve by assigning the rooms as the rooms become available, breaking ties randomly.

7. Discharge Time: Doctor use anesthesia at their own discretion and preference. We wanted to explore what effect on flow time would implementing a medically acceptable standard on the application of anesthesia. It was estimated by the doctors that the discharge time could be reduced by up to $25 \%$.

We ran a fractional factorial design (a subset of 10 scenarios) as shown in Table 7 . Each scenario was run for 30 replications. The selected subset requires the scheduling of 80 patients per day, except the first one, which represents the status quo. 
Table 7: Scenarios

\begin{tabular}{|c|c|c|c|c|c|c|c|}
\hline & F1 & F2 & F3 & F4 & F5 & F6 & F7 \\
\hline 1 & $\begin{array}{c}\text { Random } \\
\text { (0 to 7) }\end{array}$ & As Is & As Is & No & 20 & Preferential & As Is \\
\hline 2 & Constant 5 & As Is & As Is & No & 20 & Preferential & As Is \\
\hline 3 & Constant 5 & As Is & As Is & No & 20 & Random & As Is \\
\hline 4 & Constant 5 & As Is & $+2: 1 @ 7-9 / 1 @ 1-3$ & No & 20 & Random & As Is \\
\hline 5 & Constant 5 & As Is & $+2: 1 @ 7-9 / 1 @ 1-3$ & Yes50 & 20 & Random & As Is \\
\hline 6 & Constant 5 & shift - 30 min & $+2: 1 @ 7-9 / 1 @ 1-3$ & Yes50 & 20 & Random & As Is \\
\hline 7 & Constant 5 & shift - 30 min +0.2 RN & $+2: 1 @ 7-9 / 1 @ 1-3$ & Yes50 & 20 & Random & As Is \\
\hline 8 & Constant 5 & shift -30 min +1.5 RN & $+2: 1 @ 7-9 / 1 @ 1-3$ & Yes75 & 20 & Random & Reduce by 25\% \\
\hline 9 & Constant 5 & shift -30 min +1.5 RN & $+2: 1 @ 7-9 / 1 @ 1-3$ & Yes75 & 20 & Random & As-Is \\
\hline 10 & Constant 5 & shift - 30 min+2 RN & $+2: 1 @ 7-9 / 1 @ 1-3$ & Yes75 & 20 & As Is & Reduce by 25\% \\
\hline
\end{tabular}

\section{DISCUSSION OF RESULTS}

We looked at the following key measures of performance: Flow time, Wait time, Throughput, and Utilization of all resources. Except for the AS-IS scenario (SC1), all scenarios were under stress as 80 patients are scheduled. As we can see in Figure 5, requiring 80 patients without any changes to the facility (SC2) increases the flow time by $1 / 3$. However, as the operational policies are changed, and some additional resources are added, flow time decreases to a level better than the AS-IS, while processing 80 patients instead of 50. It is worth noting that the flow time increases again in SC10 because, in this scenario, we have embedded changes to the system that move the bottlenecks that were forming at the Pre/Post Op beds to the rooms turn around activity. Figure 6 shows how the contribution of the wait time for the procedure room begins to increase again in $\mathrm{SC} 10$, and it is because now patients cannot be moved to the rooms themselves, whereas before they could not be moved into the beds. But most importantly, under $\mathrm{SC} 10$, the room assignment is preferential (AS-IS). There is no doubt that such preferential assignment of rooms stresses the system even when resources to remove bottlenecks have been added. SC9 offers the best flow time, with relative minor changes in operational policies and FTE, and it also allows the processing of 80 patients per day (Figure 7).

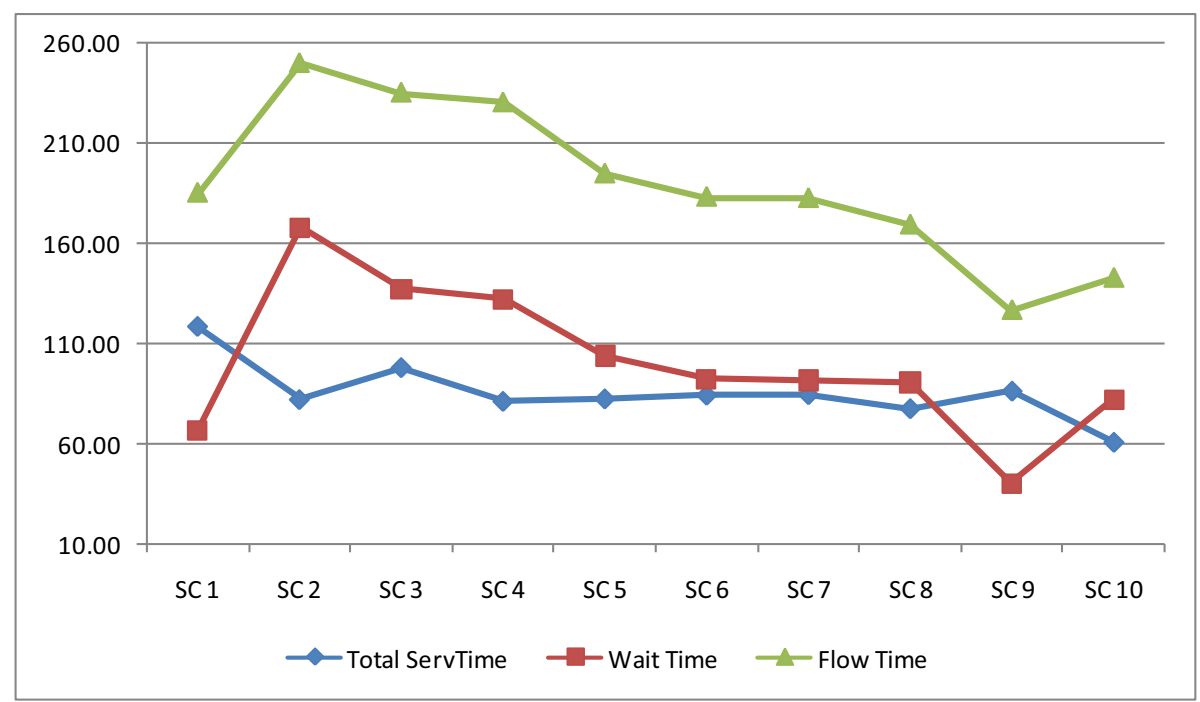

Figure 5: Flow Time and Wait Time 




Figure 6: Shifting of wait time



Figure 7: Throughput 
In regards the utilization of resources, when stressing the system with the scheduling of 80 patients per day, all utilizations go through the roof; in fact, doctors punch thru the roof because they are required to put some over time (1.06 utilization), and they still cannot process all 80 patients. As polices are changed and some resources added, the levels of utilization converge for all resources, until the system stresses out because a new bottleneck forms at the room turn around activity (Figure 8, SC10).

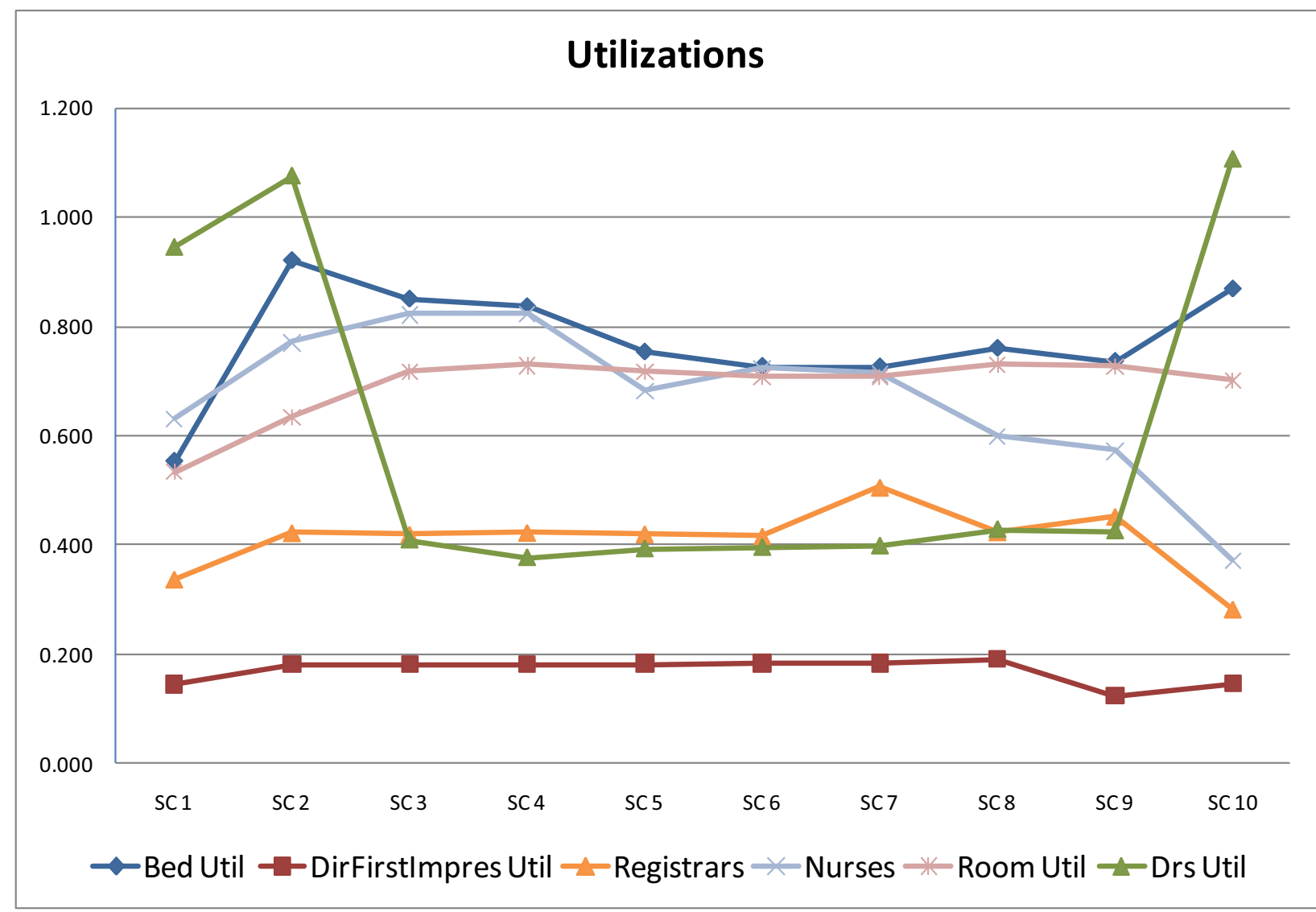

Figure 8: Utilizations

\section{CONCLUSION AND POTENTIAL EXTENSIONS}

From this study, we concluded that scenario 9 is the best among the explored scenarios. Specifically, the center needs to:

- Add 1.5 RN FTE,

- Shifting down the schedule of nurses by 30 minutes,

- Add one doctor to the time slots between 7 and 9 AM and to the time slots between 1 and 3 PM,

- Increase the percentage of pre-admitted patients to $75 \%$,

- Do not use preferential assignment of rooms, and

- Find ways to reduce the discharge time by $25 \%$.

Table 8 shows a summary of the recommended policies, as well as what would happen if the assignment of rooms continues to be done in a preferential fashion.

We also realized that the fractional experimentation has not given us a full picture, making difficult to pin point additional opportunities for improvement. Thus, we see opportunities for extensions to this work as follows: 
1. Consideration of different scheduling for the doctors, such as a morning-afternoon paradigm in which two hours at lunch time enable a break for the doctors as well as an opportunity to catch up with the morning backlog.

2. Consideration of a different appointment policy in which two fast procedures are not scheduled back to back. For example, scheduling to GST back to back requires a significant decrease in the turn around time of the room as well as expedience in the pre-op activity. As is, such time cannot be decreased, so doctors are left to wait longer between the two procedures.

3. It is necessary to study the effect of the lag time for early arrivals in more details so that a clearer policy can be developed as to how instruct the scheduler, patients, and the doctors.

4. Adding time slots to the current schedule is also a possibility that should also be explored as that may lead to exceeding the processing of 80 patients per day.

Table 8: Recommendations

\begin{tabular}{|c|c|c|c|c|c|c|c|}
\hline Scenario & F1 & F2 & F3 & F4 & F5 & F6 & F7 \\
\hline 1 & Random (0,7) & AS-IS & AS-IS & No & 20 & Preferential & \\
\hline 9 & 5 & $\begin{array}{c}\text { shift - 30 min+1.5 RN } \\
\text { FTE }\end{array}$ & $\begin{array}{c}\text { Add 2: 1@ 7-9; } \\
1 @ 1-3\end{array}$ & Yes75 & 20 & Random & $\begin{array}{c}\text { Reduce by } \\
25 \%\end{array}$ \\
\hline 10 & 5 & $\begin{array}{c}\text { shift - 30 min+1.5 RN } \\
\text { FTE }\end{array}$ & $\begin{array}{c}\text { Add 2:1@ 7-9; } \\
1 @ 1-3\end{array}$ & Yes75 & 20 & Random & $\begin{array}{c}\text { Reduce by } \\
25 \%\end{array}$ \\
\hline Scenario & Throughput & $\begin{array}{c}\text { \# of Patients Waiting to } \\
\text { be Admitted }\end{array}$ & $\begin{array}{c}\text { \# of Patients Wait- } \\
\text { ing - Pre-Proc }\end{array}$ & $\begin{array}{c}\text { Drs } \\
\text { Util }\end{array}$ & Bed Util & Room Util \\
\hline 1 & 57 & 4 & Decrease & $\begin{array}{c}\text { Slight Increase from } \\
\text { Current }\end{array}$ & 42.6 & 73.6 & 72.7 \\
\hline 9 & 75 & Decrease & $\begin{array}{c}\text { Slight Increase from } \\
\text { Current }\end{array}$ & 1.1 & 86.9 & 70.2 \\
\hline 10 & $\begin{array}{c}\text { Converge to } \\
80 / \text { day }\end{array}$ & & & & \multicolumn{2}{|c|}{7} \\
\hline
\end{tabular}

\section{REFERENCES}

Alvarez, A. M. and M.A. Centeno. 2000. Simulation-Based Decision Support for Emergency Rooms Systems. International Journal of Healthcare Technology and Management, 2(5/6):523-538.

Centeno, M. A., C. Albacete, D. Terzano, M. Carrillo, and T. Ogazon. 2000. A Simulation Study of the Radiology Department at JMH. In: Proceedings of the 2000 Winter Simulation Conference, ed. J. A. Joines, R. R. Barton, K. Kang, and P. A. Fishwick. 1978-1984. Piscataway, New Jersey: Institute of Electrical and Electronics Engineers, Inc.

Centeno, M. A., E. Lopez, M. Lee, H. Fernandez-Dodd, M. Carrillo, and T. Ogazon. 2001. A Simulation of Study of the Labor and Delivery Rooms at JMH. In Proceedings of the 2001 Winter Simulation Conference, ed. B. A. Peters, J. S. Smith, D. J. Medeiros, and M. W. Rohrer. 1392-1400. Piscataway, New Jersey: Institute of Electrical and Electronics Engineers, Inc.

Garcia, M. L., M. A. Centeno, C.M. Rivera, and N. DeCario.1995. Reducing Time in an Emergency Room Via a Fast Track. In Proceedings of the 1995 Winter Simulation Conference, ed. C. Alexopoulos, K. Kang, W.R. Lilegdon, D. Goldsman, 1048-1054. Piscataway, New Jersey: Institute of Electrical and Electronics Engineers, Inc.

Kelton, W. D., and Randall P. Sadowski. 2004. Simulation with ARENA. 3rd ed. New York: McGrawHill, Inc. 


\section{AUTHOR BIOGRAPHIES}

MARTHA A. CENTENO is an associate professor in the Department of Industrial and Systems Engineering at Florida International University. She has a B.S. in Chemical Engineering from Instituto Tecnológico de Estudios Superiores de Occidente (ITESO, Guadalajara, México), a M.S. in Industrial Engineering from Louisiana State University (LSU, Baton Rouge, LA), and a Ph.D. in Industrial Engineering from Texas A\&M University (College Station, TX). Her current research interests are in the design and development of integrated simulation systems, on-line goal driven simulation, and engineering education. She is a member of Alpha Pi Mu, Phi Beta Delta, Phi Eta Sigma, Phi Kappa Phi, Omega Rho, Tau Beta $\mathrm{Pi}$, IIE, INFORMS. Her email address is <centenod $\mathrm{fiu}$. edu>.

HELIDA R. DODD is the president of the Dodd Consulting Group (DCG) ), a healthcare consulting firm in Miami, Florida. She has a B.S. in Industrial and Systems Engineering from Florida International University (FIU, Miami, FL.), an MBA from University of Florida (UF, Gainesville, Fl.). ). Her area of expertise is in the area of process mapping, re-engineering, and simulation. Her email address is $<$ helidaldoddcg.com>.

MANUEL ARANDA is a senior undergraduate student pursuing a BS in Industrial and Systems Engineering at Florida International University. He transferred to FIU from the Central American University and Ave Maria University, both located in Nicaragua, where he did basic engineering courses and some advanced Industrial Engineering courses. He is interested in the application of simulation to supply chain management. He is member of Alpha Pi Mu, Omega Rho, Tau Beta Pi, Golden Key Honor Society, and IIE. His e-mail address is <maran002efiu.edu>

YULY SANCHEZ is a senior undergraduate student pursuing a BS in Industrial and Systems Engineering at Florida International University. She will graduate in the summer of 2010. She holds an internship position at UPS-Supply Chain Solutions. During her time at UPS-SCS, she has conducted time studies to estimate staffing, handling capacity, and created MS Excel Macros to automate manual processes, compile multiple reports to give order status, or serve as error prevention She is member of Alpha Pi Mu, Omega Rho, and IIE. Her e-mail address is < yulys22@live.com>. 